\title{
Assessment of nutritional status in older diabetic outpatients and related factors in Hanoi, Vietnam
}

This article was published in the following Dove Press journal:

Journal of Multidisciplinary Healthcare

\author{
Thu Thi Hoai Nguyen ${ }^{1-3}$ \\ Huyen Thi Thanh $\mathrm{Vu}^{1,3}$ \\ Tam Ngoc Nguyen ${ }^{1,3}$ \\ Huyen Thi Dao ${ }^{3}$ \\ Thanh Xuan Nguyen ${ }^{1,3}$ \\ Huong Thu Thi Nguyen 1,3 \\ Anh Kim Dang ${ }^{4}$ \\ Anh Trung Nguyen ${ }^{1,3}$ \\ Thang Pham ${ }^{1,3}$ \\ Giang Thu Vu ${ }^{5}$ \\ Bach Xuan Tran ${ }^{6,7}$ \\ Carl A Latkin ${ }^{7}$ \\ Cyrus $\mathrm{SH} \mathrm{Ho}{ }^{8}$ \\ Roger $\mathrm{CHo}^{9,10}$
}

'National Geriatric Hospital, Hanoi, Vietnam; ${ }^{2}$ Dinh Tien Hoang Institute of Medicine, Hanoi, Vietnam; ${ }^{3} \mathrm{Hanoi}$ Medical University, Hanoi, Vietnam;

${ }^{4}$ Institute for Global Health Innovations, Duy Tan University, Da Nang, Vietnam;

${ }^{5}$ Center of Excellence in Evidence-based Medicine, Nguyen Tat Thanh University, Ho Chi Minh city, Vietnam; ${ }^{6}$ Institute for Preventive Medicine and Public Health, Hanoi Medical University, Hanoi,

Vietnam; ${ }^{7}$ Johns Hopkins Bloomberg School of Public Health, Baltimore, MD, USA; ${ }^{8}$ Department of Psychological Medicine, National University Hospital, Singapore, Singapore; ${ }^{9}$ Center of Excellence in Behavioral Medicine, Nguyen Tat Thanh University, Ho Chi Minh City, Vietnam; ${ }^{10}$ Department of Psychological Medicine, Yong Loo Lin School of Medicine, National University of Singapore, Singapore, Singapore

Correspondence: Thu Thi Hoai Nguyen National Geriatric Hospital, IA Phuong Mai, Hanoi, Vietnam

Tel +8496284 I944

Email nththu.bvlk@gmail.com

\begin{abstract}
Purpose: Nutritional status is an important element for the wellness among older diabetic outpatients. This study aimed to assess the nutritional status of the older diabetic outpatient by using the Mini-Nutrition Assessment Short Form (MNA-SF) tool, and describe the relationship among related factors in older diabetic outpatients in the National Geriatric Hospital, Hanoi, Vietnam.

Patients and methods: A cross-sectional study was conducted from June to September 2015 in the National Geriatric Hospital. A total of 158 diabetic patients aged $\geq 60$ years at the Outpatient Department were included in this study. Patients were interviewed face-to-face to evaluate their nutritional status by using the MNA-SF. Socio-demographic, diabetic treatment information, frailty, exhaustion, cognitive function, hand grip strength and $4 \mathrm{~m}$ walk test were collected. Multivariate regression was used to determine factors associated with nutritional status.

Results: The mean age was $69.52(\mathrm{SD}=6.758)$ with $31 \%$ patients malnourished and at risk of malnutrition. A significant association was found between the nutritional status and exhaustion, cognitive impairment, and frailty. In multiple logistic regression, the study found that risk of malnutrition was associated with frailty $(\mathrm{OR}=8.45 ; 95 \% \mathrm{CI}=1.91-37.39)$ and cognitive impairment $(\mathrm{OR}=2.21 ; 95 \% \mathrm{CI}=1.01-4.84)$.

Conclusion: The results suggest that frailty was significantly associated with risk of malnutrition in older diabetic outpatients. Thus, early screening by nutritional assessment, and other interventions might improve the nutritional status of older outpatients with diabetes to prevent this complication and its effects.
\end{abstract}

Keywords: elderly, nutritional status, outpatients, Vietnam

\section{Introduction}

According to the $\mathrm{WHO}$, the number of people aged 60 or older is predicted to nearly double from $11 \%$ to $22 \%$ between 2000 and $2050 .{ }^{1}$ Vietnam will enter the "aged phase" in the next 20 years, and the aging index that is defined as "the number of persons 60 years old or over per hundred persons under age 15 (or children)" is projected to rise from 35.5 in 2009 to more than 100 in 2032. ${ }^{2,3}$ The aging population in developing countries such as Vietnam increases demands on the health care system and social services due to the reduced number of workers and increased retirees. There are multiple problems relating to the health condition of older people including functional ability, mental health, health-related quality of life and nutritional status in which malnutrition in old people is rather common and often leads to serious consequences. ${ }^{4}$ The double burden of malnutrition in ASEAN countries ranges 
from $5.0 \%$ in Vietnam to $30.6 \%$ in Indonesia at the household level. ${ }^{5}$ Undernutrition is caused by some of the following factors: polypharmacy, insufficient access to food, food choices, inadequate food intake, and comorbidity that restrict the nutrient absorption, the nutrient loss or a combinination of these factors. ${ }^{6,7}$ Furthermore, nutritional inadequacy in older adults is highly associated with risks of reduced functional status, reduced cognitive function, and increased mortality. $^{7}$

Additionally, functional ability and socio-economic status are major factors related to nutritional status. ${ }^{8}$ The cost of medical services and other living expenses indirectly affect the cost of daily nutrition in diabetic elderly people. In developing countries, the considerable poverty prevalence could severely impact the nutritional status of the older people. However, there has not been any published study assessing nutritional status in the elderly in Vietnam. ${ }^{9}$ The identification of malnutrition-associated factors among older diabetic outpatients is a first step to appreciate the scale and measure the health issue in Vietnam in order to develop appropriate prevention programs.

Therefore, the assessment of poor nutritional status among older people is critical. There are many screening tools that have been validated for conducting assessments of older people. ${ }^{10}$ The Mini Nutrition Assessment (MNA) is used widely. ${ }^{11,12}$ The MNA has an accuracy of $92 \%$ compared with a clinical evaluation by two specialist physicians in nutrition. ${ }^{12}$ Thus, the study was conducted to assess the nutritional status of older diabetic outpatients by using the Mini Nutrition Assessment Short Form (MNA-SF) tool $^{13}$ and assessing the relationship among factors related to nutritional status among older diabetic outpatients in the National Geriatric Hospital.

\section{Materials and methods Study design and participants}

A cross-sectional study was conducted from June to September of 2015 in the National Geriatric Hospital. Convenience sampling was adopted to recruit participants. Inclusion criteria were: 1) patient aged 60 and older in the outpatient diabetes management program; (2) agreeing to participate in the study; and 3 ) being able to communicate verbally. Among 183 patients initially recruited, 16 people declined to participate because they had a short time at the hospital and they felt uncomfortable and nine people were excluded due to missing information. Finally, a total of 158 older diabetic outpatients were included.

The Institutional Review Board of National Geriatric Hospital approved this study design and protocol. All participants were asked to give their written informed consents and in accordance with the Declaration of Helsinkibefore joining in this research. All data were secured and only the principal investigator had access in order to keep the patients' confidentiality.

\section{Variables and assessment}

Nutritional status was assessed using the Mini Nutritional Assessment-Short Form (MNA-SF). ${ }^{13}$ There are six items about weight loss, food intake, neuropsychological problems, psychological stress or acute disease, mobility and Body Mass Index (BMI). The total score ranges from 0 to 14 . Patient results were divided into three groups: malnourished (0-7 points), at risk of malnutrition (8-11 points) and normal nutritional status (12-14 points). ${ }^{12}$ Height $(\mathrm{cm})$ and weight $(\mathrm{kg})$ were measured, and BMI was calculated. ${ }^{14}$ The MNA-SF was translated into Vietnamese by a medical doctor then translated back to English by another doctor. After this step, the final version of MNA-SF in Vietnamese was used for interviewing in a pilot study with 10 patients. The questionnaire was delivered verbally to these patients.

Frailty syndrome was assessed using the Fried Frail Criteria $^{15}$ including five items: weight loss, low physical activity, exhaustion, slowness, and weakness. Participants were assigned to three groups: frail ( $\geq 3$ characteristics), prefrail (1-2 characteristics), and robust (none of the characteristics). Weight loss was defined as unintentional loss of 4.5 $\mathrm{kg}$ or more over the last year. Low physical activity was defined as needing assistance with these activities: walking for $1 \mathrm{~km}$, doing housework, and walking up and down stairs to the second floor. Exhaustion was based on self-reported "tired all the time". Slowness was identified using the "4 $\mathrm{m}$ walk test": participants who spent more than 5 seconds to walk $4 \mathrm{~m}$ at their usual pace were classified as slow. Weakness was identified by grip strength (Jamar 5030J1 hydraulic dynamometer (Sammons Preston, Bolingbrook, IL, USA) in the lowest $20 \%$ at baseline, adjusted for gender and BMI. $^{16}$

We used the simplified "Mini Cog"17 to assess cognitive status and this simple test was validated and in use at the National Geriatric Hospital, Vietnam. Participants were asked to draw a clock which indicated a time of "ten after eleven". Making a minor spacing error or other errors was classified as impaired cognition. 
Information of several potential associated factors was also obtained through questionnaires, including demographic factors (age, gender, educational level, living situation and frequency of hospital admission in the past 12 months), frailty syndrome, having stress, cognitive function, poly-pharmacy (using more than 5 drugs), duration of diagnosed with diabetes, and treatment therapy.

\section{Statistical analysis}

All computational analysis was carried out using SPSS version 21.0 (IBM Incorporation, Armonk, NY, USA). Frequency distribution table was constructed for qualitative variables; mean, variance; maximum value and minimum value were used for quantitative variables. Univariate and multivariate logistic regression were used to correlate nutritional status and other factors. The test was considered statistically significant if the resulting $P$-value was less than $<0.05$.

\section{Results}

Table 1 shows the socio-demographic characteristic of the participants. Mean age was $69.52(\mathrm{SD}=6.758)$. The proportion of female participants was $62 \%(\mathrm{n}=98)$. The majority of the participants (93\%) were living in the city or province. Most (77.9\%) of the participants had been diagnosed with diabetes for more than 5 years, and $48.1 \%$

Table I Characteristics of participants $(n=\mid 58)$

\begin{tabular}{|c|c|c|c|c|c|c|c|}
\hline \multirow[t]{2}{*}{ Characteristics } & \multicolumn{2}{|c|}{$\begin{array}{l}\text { Normal nutrition } \\
\text { status } \\
(n=109)(69 \%)\end{array}$} & \multicolumn{2}{|c|}{$\begin{array}{l}\text { Malnourished \& risk of } \\
\text { malnutrition } \\
(n=49)(31 \%)\end{array}$} & \multicolumn{2}{|c|}{ Total } & \multirow[t]{2}{*}{$P$-value } \\
\hline & $\mathbf{n}$ & $\%$ & $\mathbf{n}$ & $\%$ & $\mathbf{n}$ & $\%$ & \\
\hline Age & & & & & $\begin{array}{l}\text { Mean } \\
69.52\end{array}$ & $\begin{array}{l}\text { SD } \\
6.758\end{array}$ & \\
\hline \multicolumn{8}{|l|}{ Gender } \\
\hline Male & 47 & 43.1 & 13 & 26.5 & 60 & 38.0 & 0.047 \\
\hline Female & 62 & 56.9 & 36 & 73.5 & 98 & 62.0 & \\
\hline \multicolumn{8}{|l|}{ Age group } \\
\hline $60-69$ & 60 & 56.6 & 24 & 46.2 & 84 & 53.2 & 0.267 \\
\hline 70-79 & 39 & 36.8 & 22 & 42.3 & 61 & 38.6 & \\
\hline$\geq 80$ & 7 & 6.6 & 6 & 11.5 & 13 & 8.2 & \\
\hline \multicolumn{8}{|l|}{ Living situation } \\
\hline City/province & 103 & 94.5 & 44 & 89.8 & 147 & 93.0 & 0.283 \\
\hline Countryside & 6 & 5.5 & 5 & 10.2 & 11 & 7.0 & \\
\hline \multicolumn{8}{|l|}{ Education } \\
\hline Below high school & 11 & 10.1 & 10 & 20.4 & 21 & 13.3 & 0.077 \\
\hline High school and higher & 99 & 89.9 & 39 & 79.6 & 137 & 86.7 & \\
\hline \multicolumn{8}{|l|}{ Body mass index (BMI) } \\
\hline Underweight & 0 & 0.0 & 5 & 10.2 & 5 & 3.2 & \\
\hline Normal & 31 & 28.4 & 29 & 59.2 & 60 & 38.0 & $<0.001$ \\
\hline Overweight & 78 & 71.6 & 15 & 30.6 & 93 & 58.8 & \\
\hline$>3$ hospitalization & 2 & 1.8 & 3 & 6.1 & 5 & 3.2 & 0.154 \\
\hline \multicolumn{8}{|l|}{ Duration of diagnosed with diabetes } \\
\hline$=<5$ years & 20 & 18.3 & 15 & 30.6 & 35 & 22.1 & 0.086 \\
\hline$>5$ years & 89 & 81.6 & 34 & 68.4 & 123 & 77.9 & \\
\hline \multicolumn{8}{|l|}{ Insulin treatment } \\
\hline Yes & 57 & 52.3 & 19 & 38.8 & 76 & 48.1 & 0.116 \\
\hline No & 52 & 47.7 & 30 & 61.2 & 82 & 51.9 & \\
\hline
\end{tabular}

Notes: Bold data indicate prevalence of malnourished and risk of malnutrition in females in comparision to males. Patients with overweight body mass index was higher than underweight when comparing proportion of malnourished and risk of malnutrition. 
Table 2 Related factors to nutritional status in elderly patients $(n=158)$

\begin{tabular}{|c|c|c|c|c|c|c|c|}
\hline \multirow[t]{2}{*}{ Items } & \multicolumn{2}{|c|}{$\begin{array}{l}\text { Normal nutrition status } \\
(n=109)\end{array}$} & \multicolumn{2}{|c|}{$\begin{array}{l}\text { Malnourished \& risk of malnutrition } \\
(n=49)\end{array}$} & \multicolumn{2}{|c|}{ Total } & \multirow[t]{2}{*}{$P$-value } \\
\hline & $\mathbf{n}$ & $\%$ & $\mathbf{n}$ & $\%$ & $\mathbf{n}$ & $\%$ & \\
\hline \multicolumn{8}{|l|}{ Exhaustion } \\
\hline Normal & 95 & 89.6 & 36 & 69.2 & 131 & 82.9 & $<0.01$ \\
\hline Exhausted & 11 & 10.4 & 16 & 30.8 & 27 & 17.1 & \\
\hline \multicolumn{8}{|l|}{ Cognitive impairment } \\
\hline No & 79 & 72.5 & 23 & 46.9 & 102 & 64.6 & 0.002 \\
\hline Yes & 30 & 27.5 & 26 & 53.1 & 56 & 35.4 & \\
\hline \multicolumn{8}{|l|}{ Frail } \\
\hline No & 106 & 97.2 & 39 & 79.6 & 145 & 91.8 & $<0.001$ \\
\hline Yes & 3 & 2.8 & 10 & 20.4 & 13 & 8.2 & \\
\hline \multicolumn{8}{|l|}{ Polypharmacy } \\
\hline No & 59 & 54.1 & 32 & 65.3 & 91 & 57.6 & 0.189 \\
\hline Yes & 50 & 45.9 & 17 & 34.7 & 67 & 42.4 & \\
\hline \multicolumn{8}{|l|}{ Having stress } \\
\hline No & 83 & 75.2 & 32 & 65.3 & 114 & 72.2 & 0.198 \\
\hline Yes & 27 & 24.8 & 17 & 34.7 & 44 & 27.8 & \\
\hline
\end{tabular}

Notes: Bold data indicate higher risk of exhaustion, cognitive impairment and frailty than normal nutrition status group.

patients had been treated with insulin. A total of 49 participants had scores of 11 points or less in the MNA-SF screening, $26.5 \%$ were male and $73.5 \%$ were female. There was a statistically significant difference between nutritional status by body mass index and gender.

The majority of participants suffering from malnourishment and at risk of malnutrition (53.1\%) had cognitive impairment. Significant differences in exhaustion, cognitive impairment, and frailty were found between normal nutritional status and malnourished or at risk of malnutrition status (Table 2).

Table 3 shows the results of univariate logistic regression. Gender, cognitive impairment, and frailty were associated with risk of malnutrition.

Table 4 presents factors associated with the risk of malnutrition. In multivariable logistic regression, the study found that risk of malnutrition was associated with frailty $(\mathrm{OR}=8.45 ; 95 \% \mathrm{CI}=1.91-37.39)$ and cognitive impairment $(\mathrm{OR}=2.21 ; 95 \% \mathrm{CI}=1.01-4.84)$

\section{Discussion}

This study aimed to assess the nutritional status of older diabetic outpatients by using MNA-SF tools and identify any association among related factors including age, gender, stress, hospitalization more than 3 times, frailty, living
Table 3 Univariable logistic regression between the risk of malnutrition and characteristic of the participant $(n=\mid 58)$

\begin{tabular}{|c|c|c|c|c|}
\hline & & OR & $\begin{array}{l}P \text { - } \\
\text { value }\end{array}$ & $95 \% \mathrm{Cl}$ \\
\hline Gender & $\begin{array}{l}\text { Male } \\
\text { Female }\end{array}$ & $\begin{array}{l}1 \\
2.1\end{array}$ & 0.049 & $\begin{array}{l}- \\
1.003-4.39\end{array}$ \\
\hline Age group & $\begin{array}{l}60-69 \\
70-79 \\
\geq 80\end{array}$ & $\begin{array}{l}\mathrm{I} \\
1.48 \\
2.42\end{array}$ & $\begin{array}{l}0.285 \\
0.148\end{array}$ & $\begin{array}{l}- \\
0.72-3.03 \\
0.73-7.97\end{array}$ \\
\hline Low education & $\begin{array}{l}\text { No } \\
\text { Yes }\end{array}$ & $\begin{array}{l}1 \\
0.48\end{array}$ & 0.083 & $\frac{-}{0.17-1.11}$ \\
\hline Living situation & $\begin{array}{l}\text { City/province } \\
\text { Countryside }\end{array}$ & $\begin{array}{l}1 \\
1.95\end{array}$ & 0.290 & $\overline{-}-5.57-6.73$ \\
\hline $\begin{array}{l}>3 \text { Hospital } \\
\text { admission }\end{array}$ & $\begin{array}{l}\text { No } \\
\text { Yes }\end{array}$ & $\begin{array}{l}1 \\
3.49\end{array}$ & 0.179 & $\overline{0.56-21.58}$ \\
\hline Having stress & $\begin{array}{l}\text { No } \\
\text { Yes }\end{array}$ & $\begin{array}{l}1 \\
1.61\end{array}$ & 0.200 & $\begin{array}{l}- \\
0.78-3.35\end{array}$ \\
\hline Polypharmacy & $\begin{array}{l}\text { No } \\
\text { Yes }\end{array}$ & $\begin{array}{l}1 \\
0.63\end{array}$ & 0.190 & $-\overline{0.31-1.26}$ \\
\hline $\begin{array}{l}\text { Cognitive } \\
\text { impairment }\end{array}$ & $\begin{array}{l}\text { No } \\
\text { Yes }\end{array}$ & $\begin{array}{l}1 \\
2.98\end{array}$ & 0.002 & $\frac{-}{1.48-6.00}$ \\
\hline Frailty & $\begin{array}{l}\text { No } \\
\text { Yes }\end{array}$ & $\begin{array}{l}1 \\
9.06\end{array}$ & 0.001 & $\begin{array}{l}- \\
2.37-34.65\end{array}$ \\
\hline
\end{tabular}

Notes: Bold data indicate higher risk of malnutrition than male and non-groups. 
Table 4 Multivariable logistic regression between the risk of malnutrition and characteristics of the participant $s(n=\mid 58)$

\begin{tabular}{|c|c|c|c|}
\hline & & OR & $95 \% \mathrm{Cl}$ \\
\hline Gender & $\begin{array}{l}\text { Male } \\
\text { Female }\end{array}$ & $\begin{array}{l}\text { ref } \\
1.26\end{array}$ & $\overline{0.63-3.36}$ \\
\hline Age group & $\begin{array}{l}60-69 \\
70-79 \\
\geq 80\end{array}$ & $\begin{array}{l}\text { ref } \\
1.02 \\
0.82\end{array}$ & $\begin{array}{l}- \\
0.45-2.28 \\
0.19-3.66\end{array}$ \\
\hline Low education & $\begin{array}{l}\text { No } \\
\text { Yes }\end{array}$ & $\begin{array}{l}\text { ref } \\
0.59\end{array}$ & $\overline{0.21-1.70}$ \\
\hline >3 Hospitalization & $\begin{array}{l}\text { No } \\
\text { Yes }\end{array}$ & $\begin{array}{l}\text { ref } \\
2.26\end{array}$ & $\frac{-}{0.25-20.16}$ \\
\hline Having stress & $\begin{array}{l}\text { No } \\
\text { Yes }\end{array}$ & $\begin{array}{l}\text { ref } \\
1.36\end{array}$ & $\begin{array}{l}- \\
0.59-3.13\end{array}$ \\
\hline Polypharmacy & $\begin{array}{l}\text { No } \\
\text { Yes }\end{array}$ & $\begin{array}{l}\text { ref } \\
0.50\end{array}$ & - \\
\hline Cognitive impairment & $\begin{array}{l}\text { No } \\
\text { Yes }\end{array}$ & $\begin{array}{l}\text { ref } \\
2.21^{*}\end{array}$ & $\overline{I .01-4.84}$ \\
\hline Frailty & $\begin{array}{l}\text { No } \\
\text { Yes }\end{array}$ & $\begin{array}{l}\text { ref } \\
8.45 \%\end{array}$ & $\begin{array}{l}- \\
1.91-37.39\end{array}$ \\
\hline
\end{tabular}

Notes: $* p<0.05$. Bold data indicate higher risk of malnutrition than non-groups.

in rural areas, poor education, polypharmacy, and cognitive impairment. There was also a strong association between risk of malnutrition and frailty.

This study found that $31.0 \%$ of the participants were malnourished and at risk of malnutrition according to the MNA-SF scoring. Agarwalla et al ${ }^{18}$ showed that $70 \%$ of the older people were malnourished and at risk of malnutrition in Kamrup district, Assam, India. The difference can be explained that the majority of the participants in our study (93\%) came from urban areas whereas most of the study population in the Indian study came from rural areas ${ }^{18}$ the living conditions in urban areas were likely to be generally better than those in rural areas, consequently leading to a better nutrition situation. In our study, the prevalence of malnourished and at risk was more common in females than males, consistent with the finding of a study previously done by Shivraj et al. ${ }^{19}$ The numbers suggest that there is an emerging health issue when Vietnam enters an aging population, and the nutritional condition in older people should be managed and prevented.

Diabetic condition in the elderly increases the risk of hospitalization, nursing home admissions, physical disability, and substantially suboptimal nutrition. ${ }^{20,21}$ Similar to other studies, ${ }^{22,23,24}$ malnutrition was adversely associated with cognitive impairment. ${ }^{25}$ A Swedish study found possible malnutrition in older people being associated with mild cognitive impairment. ${ }^{26}$ According to results from Vellas et $\mathrm{al}^{27}$ undernourishment was associated with the severity of Alzheimer's disease and predicted disease progression. Frailty was associated with the risk of malnutrition in the present study. This finding was in line with a Vietnamese study ${ }^{9}$ showing that poor nutritional status was found to be associated with frailty defined by either REFS or Fried phenotype in older patients in Vietnam. People with poor grip strength might encounter difficulties with meal preparation thus they were in a possible malnutrition group.

In developing countries, there is a lack of health services that focus on the well-being of the elderly regarding functional capacity and nutritional status. ${ }^{8,28,29}$ It is difficult for older people to prepare meals and cook due to frailty and low financial status. Additionally, many participants might have a lack of knowledge of proper nutrition, especially diet for diabetes disease. Out-patients may have difficulties in seeking regular advice or recommendations for healthy meals from health professionals or nutritionists. Nutritional status assessment could provide a window of opportunity to prevent malnutrition in this population and other geriatric syndromes such as falls, frailty, or low physical activity.

The findings of this study should be viewed in light of several limitations. First, the cross-sectional design limits the ability to reach any conclusion regarding causal associations between factors. Second, the sample size was relatively small and was recruited by a convenience sampling scheme, thus cannot be said to be representative of the population of Vietnam. Third, the study was only conducted with diabetic outpatients. Moreover, this study lacks consideration of other related factors that may have affected the nutritional status assessment such as the use of dietary supplements, smoking, and alcohol consumption. This calls out for more researches in the future which address the sample size issue and nutritional assessment in other populations.

\section{Conclusion}

This study underlines the association between nutritional status and related factors in older diabetic outpatients. Nearly one third of the population studied was malnourished and at risk of malutrition. This number is high thus it is important for health care providers to focus on managing the diet of diabetic patients. The results suggest that frailty and cognitive impairment were significantly associated with risk of malnutrition. Early screening, assessment and intervention can improve the nutritional status of elderly diabetics. These findings also support the need for further studies on the assessment of the 
nutrition status in old people in rural areas of Vietnam and in non-diabetic Vietnamese people.

\section{Acknowledgment}

We greatly thank Ms Nguyen Phuong Anh, Ms Dinh Kim Dung for helping with the recruitment of participants for the study and Dr Tu N Nguyen for valuable comments on the manuscript.

\section{Disclosure}

Professor Carl A Latkin reports grants from NIH, during the conduct of the study. The authors report no other conflicts of interest in this work.

\section{References}

1. WHO. Are you ready? What you need to know about ageing. World Health Day. 2012.

2. Bank TW. Live Long and Prosper Aging in East Asia and Pacific. Washington (DC): World Bank; 204332016. Available from: https:// opendevelopmentmekong.net/dataset?id=live-long-and-prosperaging-in-east-asia-and-pacific

3. Vietnam UNFPA. The aging population in Viet Nam current status, prognosis, and possible policy responses. 2011;6-17.

4. Anna Pilgrim SR, Sayer AA, Roberts H. An overview of appetite decline in older people. Nurs Older People. 2015;27(5):29-35. doi:10.7748/nop.27.5.29.e697

5. Rachmi, Li M, Baur, LA. The double burden of malnutrition in Association of South East Asian National (ASEAN) countried: a comprehensive review of the literature. Asia Pac J Clin Nutr. 2018;27(4):736-755.

6. Evans C. Malnutrition in the elderly: a multifactorial failure to thrive. Perm J. 2005;9:3.

7. Ahmed T, Haboubi N. Assessment and management of nutrition in older people and its importance to health. Clin Interv Aging. 2010;5:207-216.

8. Joweria Nambooze MF, Inaoka T. Nutritional status and functional capacity of community-dwelling elderly in Southern Laos. Environ Health Prev Med. 2013;19:367.

9. Vu HTT, Thanh XN, Pham T. Prevalence of frailty and its associated factors in older hospitalised patients in Vietnam. BMC Geriatr. 2017;17:216. doi:10.1186/s12877-017-0515-3

10. Slee A, Birch D, Stokoe D. A comparison of the malnutrition screening tools, MUST, MNA and bioelectrical impedance assessment in frail older hospital patients. Clin Nutr. 2015;34:296-301. doi:10.1016/j.clnu.2014.04.013

11. Leslie W, Hankey C. Aging, nutritional status and health. PMC. 2015;3(3):648-658.
12. B V, Villars H, Abellan G, et al. Overview of the MNA - its history and challenges. Nutr Health Aging. 2016;10:456-465.

13. Kaiser MJ, Bauer JM, Ramsch C. Validation of the mini nutritional assessment short-form (MNA®-SF): a practical tool for identification of nutritional status. $J$ Nutr Health Aging. 2009;13:782-788.

14. Consultation WE. Appropriate body-mass index for Asian populations and its implications for policy and intervention strategies. Lancet. 2004;363(9403):157-163. doi:10.1016/S0140-6736(03)15268-3

15. Fried L P Tangen CM, Walston J, et al. Frailty in older adults: evidence for a phenotype. J Gerontol Med Sci. 2001;56A(3):146-156.

16. Lee JE, Kim KW, Paik NJ, et al. Evaluation of factors influencing grip strength in elderly Koreans. J Bone Metab. 2012;19(2):103-110. doi:10.11005/jbm.2012.19.2.103

17. Borson S, Scanlan JM, Chen P, Ganguli M. The mini-cog as a screen for dementia: validation in a population-based sample. JAGS. 2013;51(10):1451-1454. doi:10.1046/j.1532-5415.2003.51465.x

18. Agarwalla R, Saikia A, Baruah R. Assessment of the nutritional status of the elderly and its correlates. J Family Community Med. 2015;22(1):39-43. doi:10.4103/2230-8229.149588

19. Shivraj M, Singh V, Meena B, Singh K. Study of nutrition status in elderly in Indian population. Int J Curr Res. 2014;6(11):1025310257.

20. Russell LB, Valiyeva E, Roman SH. Hospitalizations, nursing home admissions, and deaths attributable to diabetes. Diab Care. 2015;28 (7):1611-1617. doi:10.2337/diacare.28.7.1611

21. Gregg EW, Beckles GL, Williamson DF. Diabetes and physical disability among older US adults. Diab Care. 2000;23(9):1272-1277. doi:10.2337/diacare.23.9.1272

22. Shahar S, Ibrahim Z, Fatah AR. A multidimensional assessment of nutritional and health status of rural elderly Malays. Asia Pac J Clin Nutr. 2007;16:346-353.

23. Oliveira MR, Fogaca KC, Leandro-Merhi VA. Nutritional status and functional capacity of hospitalized elderly. Nutr J. 2009;17(8):54.

24. Olayiwola IO, Ketiku AO. Socio-demographic and nutritional assessment of the elderly Yorubas in Nigeria. Asia Pac J Clin Nutr. 2006;15:95-101.

25. Daradkeh G Essa MM. Nutritional status and cognitive impairment in elderly. Pak J Biol Sci. 2014;17(10):1098-1105.

26. Johansson L, Sidenvall B, Malmberg B, et al. A prospective study of factors associated with malnutrition in older persons living at home. $J$ Nutr Health Aging. 2009;13:855-861.

27. Vellas B, Lauque S, gillette-Guyo Nnet S, et al. Impact of nutritional status on the evolution of Alzheimer's disease and on response to acetylcholinesterase inhibitor treatment. $J$ Nutr Health Aging. 2005;9:75-80.

28. Tanvir ANH. Nutritional status and functional capacity of community-dwelling elderly. Clin Interv Aging. 2010;5:207-216.

29. Adebusoye LA, Ajayi IO, Dairo MD, Ogunniyi AO. Nutritional status of older persons presenting in a primary care clinic in Nigeria. J Nutr Gerontol Geriatr. 2012;31(1):71-85. doi:10.1080/ 21551197.2012.647560
Journal of Multidisciplinary Healthcare

\section{Publish your work in this journal}

The Journal of Multidisciplinary Healthcare is an international, peerreviewed open-access journal that aims to represent and publish research in healthcare areas delivered by practitioners of different disciplines. This includes studies and reviews conducted by multidisciplinary teams as well as research which evaluates the results or conduct of such teams or healthcare processes in general. The journal covers a very wide range of areas and welcomes submissions from practitioners at all levels, from all over the world. The manuscript management system is completely online and includes a very quick and fair peer-review system. Visit http://www.dovepress.com/testimonials. php to read real quotes from published authors. 